\title{
O combate em contexto de arte e jogo: contribuições artísticas e lúdicas para o ensino da marcialidade
}

\author{
Gilbert de Oliveira Santos ${ }^{1}$
}

\begin{abstract}
RESUMO
As artes marciais podem apresentar elementos expressivos e lúdicos que potencializam a dimensão artística e entusiasmante do gesto. Neste contexto, não basta apresentar somente poder marcial, é preciso trazer ao corpo e ao gesto contentamento e beleza, alargando o ensino das artes marciais. $\mathrm{O}$ objetivo deste trabalho é apresentar uma discussão a respeito dos fatores que aproximam a arte marcial das artes e do jogo com ênfase no conceito de mímesis, entendida aqui como uma ação interpretativa que busca se aproximar com precisão da beleza do gesto sem perder de vista a ludicidade e a subjetividade do ato. Para defender e reforçar a relação entre arte, jogo e arte marcial, será apresentado um conjunto de atividades de ensino que favorecem a apropriação de elementos artísticos e lúdicos no ensino de artes marciais.
\end{abstract}

PALAVRAS-CHAVE: Artes Marciais. Arte. Jogo. Ensino. Mímesis.

The combat in the context of art and game: artistic and playful contributions to the teaching of martiality

\begin{abstract}
Martial arts can present expressive and playful elements that potentiate the artistic and thrilling dimension of the gesture. In this context, it is not enough to present only martial power, it is necessary to bring to the body and gesture contentment and beauty, extending martial arts teaching. The aim of this paper is to present a discussion about the
\end{abstract}

\footnotetext{
${ }^{1}$ Professor Doutor da Universidade Federal dos Vales do Jequitinhonha e Mucuri, Campus de Diamantina-MG, Brasil. https://orcid.org/0000-0002-1237-9308.gilbert.santos@ufvjm.edu.br.
} 
factors that bring martial art closer to the arts and play with emphasis on the concept of mimesis, understood here as an interpretive action that seeks to approach the beauty of the gesture without losing sight of the playfulness and subjectivity of the act. To defend and reinforce the relationship between art, game and martial art, it will be presented a set of teaching activities that favor the appropriation of artistic and playful elements in the teaching of martial arts.

KEYWORDS: Martial Arts. Art. Game. Teaching. Mímesis.

\section{Introdução}

No contexto das práticas corporais ${ }^{2}$ é o aspecto marcial do gesto que diferencia as artes marciais de outras práticas e conhecimentos sobre o corpo, ou seja, a origem e o desenvolvimento do gesto marcial pressupõem o princípio de um combate.

Marte, deus romano da guerra, dá origem ao termo marcial. Dentro da mitologia greco-romana, Bulfinch (2000) aponta que Marte nutria grande amor pela violência e pelo derramamento de sangue, sendo apresentado na obra Ilíada atribuída a Homero (2005), como um gigante peludo, estúpido e desajeitado, entretanto, invencível em batalhas!

De fato, não apenas o termo, mas a própria origem e essência das artes marciais relacionam-se com o tema da guerra. No entanto, de um ponto de vista pedagógico, não seria um reducionismo relacionar as artes marciais única e exclusivamente ao aspecto combativo? Será que somente a dimensão marcial dessas práticas deve ser priorizada? Que outras qualidades o gestual das artes marciais podem proporcionar além do aspecto de combate físico?

Correia e Franchini (2010) definem as artes marciais como práticas corporais que derivam de técnicas de guerra e que apresentam de maneira

\footnotetext{
${ }^{2}$ As práticas corporais são fenômenos que se mostram no plano corporal, constituindo-se em manifestações culturais de caráter lúdico, tais como os jogos, as danças, as ginásticas, os esportes, as artes marciais, entre outras (Silva et al., 2014).
} 
proeminente a dimensão ética e estética, sinalizando para aspectos expressivos, inventivos, imaginários, lúdicos e criativos. Os autores ainda apontam que as artes marciais ultrapassam as demandas pragmáticas e utilitaristas das formas militares e bélicas de combate. Espartero (1999) também aponta que além de preparação para a guerra e autodefesa, as artes marciais podem apresentar-se na forma de jogo ou como ação ritualística.

Logo, a arte marcial não precisa direcionar-se exclusivamente para a dimensão combativa, podendo ser apreciada também em contexto de arte e jogo. Entretanto, atualmente é um desafio chamar a atenção para a expressividade e ludicidade nas artes marciais, tendo em vista a predominância dos aspectos esportivos e de eficácia marcial em seu contexto.

Arte e jogo estimulam o potencial criativo e contribuem para incrementar o entusiasmo pelo conhecimento, por isso, concorrem para uma abordagem pedagógica mais ampla e prazerosa de ensino da arte marcial.

Este artigo pretende explorar a dimensão artística e lúdica do gesto marcial, apresentando uma discussão a respeito dos fatores que aproximam a arte marcial do campo das artes e do jogo com ênfase no debate a respeito da mímesis marcial, entendida aqui como uma ação interpretativa que busca se aproximar com precisão da beleza do gesto sem perder de vista o lúdico e a subjetividade de quem realiza este ato. Além disso, serão apresentadas algumas atividades desenvolvidas no âmbito da formação em educação física que visam aproximar os estudantes da experiência artística e lúdica do combate. O intuito maior deste trabalho é contribuir no processo de reflexão e discussão a respeito do ensino e da aprendizagem das artes marciais.

\section{Arte e Arte Marcial}

Se em "contexto real" o combate físico possui limites pedagógicos de abordagem, é na dimensão artística e lúdica que este conhecimento pode ser experimentado acrescido de beleza e prazer. Ao invocar arte e jogo no gesto 
marcial, destitui-se em parte seu caráter pragmático e utilitarista em prol de um caráter mais expressivo e prazeroso que irá ampliar as possibilidades pedagógicas do gesto marcial de uma maneira que nem o esporte ou a autodefesa realizam, pois ambos especializam e racionalizam o gesto marcial.

Numa competição, um atleta de combate está condicionado à necessidade de vencer seu oponente fisicamente, o que especializa e racionaliza os seus gestos para este fim. De fato, alguns atletas de combate tornam-se campeões se especializando em apenas uma ou duas técnicas. Já a autodefesa, limita as possibilidades de aprendizado dos gestos marciais a simulação de possíveis situações de ataque pessoal.

Portanto, em contexto esportivo ou de autodefesa, o gesto marcial direciona-se para a eficiência atlética e/ou marcial, restringindo outras possibilidades pedagógicas para o ensino das artes marciais.

As artes marciais possuem relação com a arte e o jogo? Quais seriam essas relações? De fato, uma vez que as questões artísticas e lúdicas da arte marcial raramente são objetos de pesquisa, é duvidoso o uso do termo arte em contextos em que se pouco valoriza o aspecto artístico e lúdico do gesto marcial.

Chamar a atenção da arte e do jogo na arte marcial pode potencializar a dimensão expressiva e lúdica do gesto marcial, entretanto, tal contribuição pode contrariar uma dimensão mais pragmática, pois:

Pragmatismo e valor estético sempre tiveram relação conflituosa. Isso não indica dizer que aquilo que é belo mostra-se, necessariamente, inútil. Mas, por outro lado, do ponto de vista estético, aquilo que é belo não precisa ser, necessariamente, útil. (ROBLE ET AL., 2013, p.547).

A posição aqui assumida é a da defesa do componente artístico e lúdico da arte marcial, uma vez que a prevalência do termo arte exige uma 
adequação ao significado artístico, do contrário, o mais adequado seria a utilização de outras nomenclaturas mais apropriadas, tais como esportes de combate, lutas, modalidades esportivas de combate, técnicas de autodefesa etc.

Em contexto de arte, é possível criar outros mundos além do real, pois: "O que não temos, ou não ousamos, ou não conseguimos, podemos possuí-lo em sonho, e é com esse sonho que fazemos arte." (PESSOA, 2006, p.234). Não é à toa que muitas linguagens artísticas utilizam das artes marciais como inspiração. Seja no cinema, dança, teatro, fotografia ou nas artes plásticas, há uma dimensão expressiva das artes marciais que facilita uma exploração artística do corpo em contexto de combate.

No cinema contemporâneo, muitos filmes exploram as técnicas marciais potencializando a dimensão imaginária do combate, na medida em que as personagens, graças também a tecnologia cinematográfica, são capazes de realizar movimentos de grande beleza e plasticidade. As óperas, o teatro e a dança também se aproveitam da dimensão lúdica e expressiva das artes marciais. ${ }^{3}$ Compondo junto com a música e o canto, estas linguagens incorporam algumas técnicas marciais que possibilitam a ampliação da carga dramática dos espetáculos. Já no âmbito da pintura e da fotografia, muitas obras de Carybé e Pierre Verger, por exemplo, se inspiraram na capoeira.

Inserindo elementos de ordem expressiva, algumas técnicas marciais passam a ser dotadas de uma plasticidade corporal que inevitavelmente as conduzem para o campo das artes. Essa capacidade está ligada ao reconhecimento dos aspectos simbólicos da realidade que possibilitam o prazer da experiência estética.

Mesmo que as técnicas marciais estejam muito coladas na lógica da danificação, é possível expandir elementos menos bélicos tais como plasticidade, beleza, elegância, postura, harmonia, controle, etc. Desse

\footnotetext{
${ }^{3}$ Cursive é um espetáculo de dança do Grupo Cloud Gate Dance Theatre of Taiwan que se inspira na caligrafia e artes marciais chinesas em sua composição. Já o artista brasileiro Antonio Nóbrega, faz da capoeira uma arte corporal de dança, jogo, música e teatro.
} 
modo, realça-se contornos pouco evidentes ou até mesmo desconhecidos por muitos praticantes de artes marciais.

Arte em latim é ars e significa técnica, habilidade. Técnica deriva de tecné, expressão grega que no período clássico abarcava duas vertentes. Uma relacionada ao fazer artístico e outra relacionada ao conjunto de regras que possibilita orientar e agenciar qualquer atividade (FENSTERSEIFER, 2014).

Logo, a arte não destitui do gesto marcial o seu aprimoramento técnico. Aliás, esta acepção de arte está bem estabelecida no contexto das artes marciais, pois tanto o esporte como a autodefesa prezam pelo aprimoramento técnico. No entanto, arte marcial enquanto um fazer artístico ligado ao sensível não é comum, pois desse modo, a técnica marcial estaria livre da condição sine qua non de comparação de desempenho ou de precisão combativa e também poderia direcionar-se para aspectos mais simbólicos e subjetivos do gesto:

Arte é a atividade que supõe criação de sensações ou de estados de espírito, de caráter estético carregados de vivência pessoal e profunda, podendo suscitar em outrem o desejo de prolongamento ou renovação (FERREIRA, 2005, p.176).

Esta passagem das artes marciais para o campo das artes e do jogo é ainda mais favorecida quando se estimula a mímesis gestual, pois no ato de mimetizar a água, o fogo ou um animal em contexto de combate, já se cria um mundo de fantasia, característica privilegiada de aprendizado e deleite humano:

A mímesis designa um processo de aprendizado específico do homem (e, em particular, das crianças). A aquisição de conhecimentos é favorecida pelos aspectos prazerosos do processo. Poderíamos dizer, nesse sentido, que o impulso mimético está na raiz do lúdico e do artístico (GAGNEBIN, 2005, p.84). 
Muitos movimentos das artes marciais se baseiam na mimetização da natureza, que conforme Caillois (1990), seria um tipo de jogo que pressupõe a encarnação de uma personagem ilusória e a adoção de seu respectivo comportamento. O prazer é o de ser um outro ou de se fazer passar por outro, o que inevitavelmente aproxima este tipo de jogo da representação teatral e dramática. Caillois (1990) nomeia estes jogos de mimicry: "O mimicry consiste na representação deliberada de uma personagem, o que facilmente se torna uma obra de arte, de cálculo e de astúcia." (CAILLOIS, 1990, p.99).

É interessante perceber que muitos gestos marciais trazem em sua configuração uma representação mimética. Às vezes, o próprio título da técnica apresenta a discriminação da mímesis realizada. Também é comum recorrer-se a imagens miméticas para potencializar o entendimento do aspecto físico e/ou emocional que se almeja e, finalmente, é bastante usual aprender arte marcial através da mímesis do/a mestre/a:

É preciso ter fé e confiança nos mestres. É muito importante encontrar um bom mestre. Só de ver alguns praticantes, é possível saber quem são os mestres dele, pois o aluno adquire o mesmo estilo do mestre (REID; CROUCHER, 1983, p.243-244).

Porém, não se trata aqui de pensar a mímesis apenas como imitação e repetição mecânica, mas como um fazer com expressividade criativa e originalidade. Logo, o ato mimético não é mera reprodução, mas ação criativa: "Mímesis não significa simples imitação no sentido de produzir cópias. Ela se refere a uma qualidade criativa do homem que lhe permite realizar algo novo" (WULF, 2005, p. 103). Desse modo, as características miméticas favorecem a aproximação dos aspectos criativos e lúdicos do gesto e, por isso, facilitam uma condição ampliada de aprendizagem do gesto marcial. 
Breda et al. (2010) apontam que no contexto de ensino das artes marciais prevalecem modelos em que os conteúdos são transmitidos como verdades absolutas, preponderando à repetição mecânica de gestos, além de uma relação de aprendizagem que limita os alunos à imitação passiva. Daí a necessidade do ensino das artes marciais estar envolto em abordagens pedagógicas focadas nas pessoas e não somente nas técnicas, contribuindo para que o processo de ensino não se reduza apenas ao domínio de habilidades ou técnicas pré-estabelecidas (RUFINO; DARIDO, 2012).

A dimensão artística e lúdica pode contribuir em instigantes e inovadoras formas de ensinar artes marciais, fomentando o prazer pelo movimento e a pesquisa por melhores qualidades expressivas do gesto. Desta pesquisa, podem surgir técnicas com maior beleza, plasticidade e traços mais subjetivos do praticante.

Trata-se, portanto, da pesquisa e do aprimoramento dos movimentos que melhor se adaptam a cada um, de modo que as técnicas surjam dotadas de potência física e também de traços mais subjetivos, agregando ao gesto mais organicidade e originalidade, pois como diz Gombrich (1999), nada existe realmente a que se possa dar o nome Arte, existem somente artistas.

\section{Em busca de si mesmo}

Para que as artes marciais possam promover uma expressão gestual mais genuína, é preciso que tanto a forma como o conteúdo de ensino persistam no princípio da pesquisa e realização de/do si à partir do gesto (SANTOS; BRAGANÇA, 2019). Esta honestidade gestual foi paradoxalmente apontada pelo principal responsável pela ascensão da ficção marcial no cinema, o artista e filósofo chinês Bruce Lee:

Para mim, em última instância, arte marcial significa expressar-se honestamente. Agora, isto é muito difícil de fazer. Quero dizer, é fácil para mim fazer um show e ser arrogante, e ser inundado com 
uma sensação arrogante e depois se sentir muito legal e tudo isso. Ou eu posso fazer todos os tipos de coisas falsas, você sabe o que quero dizer, - e ser cegado por isto. Ou eu posso mostrar-lhe algum movimento realmente sofisticado. Mas se expressar honestamente, não mentir para si mesmo e expressar-me honestamente - agora, isso, meu amigo, é muito difícil de fazer (LEE, 1971). ${ }^{4}$

Esta autenticidade propõe o reconhecimento das próprias tendências de movimento no caminho oposto da automatização, equilibrando modelos e formas definidas com a busca pessoal de maior originalidade gestual. Assim, além dos gestos transmitidos, é preciso deixar espaço para que os gestos também possam ser criados, pois assim, amplia-se a consciência de si e do gesto e a capacidade de entendimento da essência das técnicas.

A arte surge do domínio da técnica. É preciso técnica para fazer arte, mas somente técnica não é suficiente para fazer arte. Para fazer arte é preciso se aproximar do que Valéry (2003) chamou de inspiração, um estado que permite ao artista adaptar uma técnica as suas potencialidades particulares e ao seu desejo expressivo.

Assim, a arte marcial pode possibilitar o desenvolvimento da expressividade de maneira global, é o que destacam Rosseto; Andraus (2015) a partir da entrevista dada por Bruce Lee a Pierre Berton em 1971:

Pelo menos da maneira como eu ensino, todo o tipo de conhecimento significa autoconhecimento. Portanto, as pessoas veem até mim pedindo para que lhes ensine, não tanto como se defender ou como atacar outro. Em vez disso, eles querem aprender a expressar-se através de algum movimento, seja a raiva, seja a determinação ou qualquer coisa assim. Então, em

\footnotetext{
${ }^{4}$ Tradução livre da entrevista de Bruce Lee concedida a Pierre Berton em 9 de dezembro de 1971. Disponível em: <https://www.youtube.com/watch?v=VEGTk1qGnRg> Acesso em 20 de Maio de 2018. No original: To me, ultimately, martial art means honestly expressing yourself. Now, it is very difficult to do. I mean, it is easy for me to put on a show and be cocky, and be flooded with a cocky feeling and then feel like pretty cool and all that. Or I can make all kinds of phony things, you know what I mean, - blinded by it. Or I can show you some really fancy movement. But to express oneself honestly, not lying to oneself and to express myself honestly - now, that, my friend, is very hard to do.
} 
outras palavras, o que estou dizendo é que me pagam para mostrar-lhes, de forma combativa, a arte de expressar-se com o corpo humano (LEE, 1971). ${ }^{5}$

Trata-se, portanto, de despertar uma forma de inteligência corporal, capaz de desenvolver capacidades físicas aliadas ao cultivo da criatividade e do autoconhecimento. $\mathrm{O}$ objetivo é dirigir-se à própria essência aprendendo a conhecer e a respeitar os limites e possibilidades do próprio corpo.

Considerando isto, agora será apresentado uma síntese do trabalho realizado na disciplina Artes Guerreiras do Departamento de Educação Física da Universidade Federal dos Vales do Jequitinhonha e Mucuri, Campus de Diamantina-MG.

Atualmente, esta disciplina é oferecida a dois cursos de graduação (licenciatura e bacharelado) em educação física que ocorre no terceiro semestre letivo de ambos os cursos. Com quantitativo médio de 32 alunos/as por semestre, o processo pedagógico é conduzido com ênfase na dimensão da pesquisa e experimentação do gesto marcial, considerando o domínio do corpo e do gesto em postura de bipedia, em projeção/elevação ao/do chão e no solo. Tal divisão é fruto de uma longa odisséia em inúmeras técnicas marciais e visa explorar as diferentes possibilidades gestuais presentes na maior parte das práticas corporais marciais, uma vez que a disciplina se propõe a abordar as artes marciais de maneira mais ampla do que centrarse nos aspectos de uma única técnica. Deste modo, é reforçado a proposição de Del Vecchio; Franchini (2006), que apontam que a abordagem das artes marciais no âmbito da formação em educação física não deve centrar-se apenas em uma prática isolada de uma ou outra modalidade, mas propiciar a aprendizagem de conceitos, procedimentos e atitudes que auxiliem os

\footnotetext{
5 Tradução livre da entrevista de Bruce Lee concedida a Pierre Berton em 9 de dezembro de 1971. Disponível em: <https://www.youtube.com/watch?v=VEGTk1qGnRg> Acesso em 20 de Maio de 2018. No original: (...) or at least the way that when I teach it, all type of knowledge means self-knowledge. So, therefore they are coming in and asking me to teach them, not so much of how to defend themselves or how to do somebody in. Rather, they want to learn to express themselves through some movement, be it anger, be it determination or whatsoever. So, in other words, what I'm saying is, he's paying me show him, in combative form, the art of expressing the human body.
} 
estudantes a analisar criticamente a arte marcial, compreendendo os processos didáticos que os possibilitem aprender e ensinar.

A ementa da disciplina propõe o desenvolvimento do entendimento dos princípios artísticos, filosóficos, marciais, terapêuticos e pedagógicos das artes marciais com base, sobretudo, na ludicidade e na expressão do gesto. Entretanto, será acentuado aqui os aspectos artísticos e lúdicos que se relacionam com a ampliação e aperfeiçoamento da gestualidade, o desenvolvimento da expressão do gesto e o entusiasmo pela arte marcial.

\section{Algumas atividades de ensino de artes marciais na formação em educação física}

- Golpes: Simulação de um ataque ou defesa usando os membros superiores e inferiores. Algumas artes marciais adotam o princípio da cintura como centro organizador dos movimentos das extremidades do corpo, pois isso unifica a força e amplia a potência dos golpes. Assim, antes de praticar a emissão de golpes, é preciso perceber a organização correta do corpo e o caminho de unificação que a força marcial percorre até ser transmitida de maneira mais eficiente nas mãos ou nos pés.

Nesta etapa, estuda-se a emissão do poder marcial de forma isolada, na qual a força física e a concentração mental atuam conjuntamente. $O$ caminho de unificação da força inicia-se nos pés a partir da reação do chão, desenvolve-se nas pernas, é controlado pela cintura e se expressa nas extremidades do corpo. Trata-se de uma organização que unifica a força do corpo e favorece a coordenação corporal para o exercício da marcialidade.

Durante o estudo, os golpes podem ser emitidos de maneira controlada ou súbita, explorando-se diferentes direções e sentidos ou mesmo realizando-os em deslocamento. Busca-se assim, ampliar as possibilidades expressivas do gesto durante a emissão do poder marcial, o que será importante em outras etapas de ensino. 
- Seqüência Marcial: Gomes (2008) define as seqüências marciais como a combinação de técnicas tradicionais que expressam a essência dos movimentos dos diferentes estilos, arranjados numa seqüência préestabelecida e que podem ser executados na presença de oponentes reais ou imaginários.

As seqüências marciais são movimentos executados de maneira encadeada e sem interrupção, o princípio de um movimento é o fim do movimento precedente. Em cada movimento, há a presença de aplicações e princípios marciais que precisam ser compreendidos, pois do contrário, os movimentos tornam-se apenas uma espécie de ginástica acrobática desprovida de caráter combativo.

A preocupação inicial dos estudantes é conseguir realizar uma seqüência em sua ordem correta para, posteriormente, prosseguir para uma nova seqüência com grau de dificuldade superior. No entanto, mesmo em uma seqüência marcial mais simples, é possível chamar a atenção para detalhes estéticos e expressivos que irão exigir maior cuidado e elegância durante a sua execução. Detalhes como a plasticidade, beleza, harmonia, autocontrole, ritmo, etc., aprimoram a dimensão artística do gesto e sensibilizam o estudante para a experiência estética da arte marcial.

Em mandarim, estas seqüências marciais de movimento são conhecidas por tàolù (套路), mas no Brasil são mais conhecidos os termos formas, katas, katis ou poomsaes. É interessante fazer uso de diferentes estilos e formas de seqüência, como também pequenos fragmentos de diferentes estilos, o que facilita a repetição, a memorização e o aprimoramento da técnica, pois em apenas uma parte da seqüência, muitos princípios podem ser percebidos.

Uma vez compreendido a existência de alguns princípios técnicos que são feitos na execução dos golpes ou nas seqüências marciais, pode-se ampliar as qualidades dinâmicas de movimento, incrementando a expressividade e os aspectos artísticos do gesto. 
- Pesquisa Gestual: Aprender arte marcial é aprender golpes de ataque e defesa, no entanto, incluir uma outra possibilidade pedagógica que não a exclusiva simulação de um combate, permite explorar e ampliar outros aspectos do ensino das artes marciais.

Laban (1978) aponta quatro fatores que auxiliam na ampliação das qualidades expressivas do movimento. São estes a fluência, o espaço, o peso e o tempo.

$\mathrm{O}$ peso pode transitar entre o firme e o leve, resultando na diferenciação da sensação de movimento leve ou pesada. O esforço pode transitar entre o súbito e o sustentado, resultando na diferenciação da sensação instantânea ou de longa duração do movimento. O espaço pode transitar entre o direto e o flexível, resultando na diferenciação da direção e sensação do movimento como uma linha reta ou flexível no espaço. E a fluência pode transitar entre a livre e a controlada, resultando na diferenciação da prontidão de interromper ou não o fluxo do movimento (LABAN, 1978).

Após o entendimento e a experimentação destes fatores de movimento, os estudantes passam a vasculhar quais são as suas melhores qualidades gestuais na criação de um conjunto de movimentos marciais. Assim, realiza-se a experimentação das técnicas marciais esquivando-se dos códigos predeterminados e da incisiva condição de pensar o gesto dotado da máxima eficiência combativa. No entanto, pode surgir a necessidade de chamar a atenção para uma condição mínima de marcialidade, pois durante esta pesquisa de movimento, os estudantes podem incorrer no erro de desenvolver técnicas desprovidas totalmente de objetivos e intenções marciais.

O objetivo desta pesquisa é potencializar a criatividade dos estudantes e buscar maior fluência e genuidade na execução dos gestos marciais, já que muitos golpes e/ou seqüências marciais, contém diversos detalhes e/ou exigências físicas que dificultam a sua execução de maneira fluída pelo estudante inexperiente. A pesquisa do gesto é uma forma de 
improvisação que objetiva promover a criatividade e a busca de autenticidade gestual, estimulando o estudante a encontrar a melhor maneira de elaborar a expressão de si, sem perder de vista os princípios técnicos que constituem parte essencial do aprendizado de uma arte marcial: "Improvisar é criar, jogar, arriscar, transformar uma ideia num espaço privilegiado para concepções poéticas e simbólicas" (ROSSETO; ANDRAUS, 2015, p. 80).

Para enriquecer ainda mais esta pesquisa, pode-se conduzi-la para diversificadas investigações, tais como a exploração do espaço e o uso de diferentes direções \{frente, trás, direita, esquerda, diagonais\}, diferentes níveis \{alto, baixo, médio\}, a execução de giros entre os movimentos, a descoberta e exploração de diferentes bases dos pés, diversas formas de mãos (fechada, aberta, faca da mão, gancho, garra) e também dos pés (dorso, lateral, calcâneo, ponta, planta), etc.

A pesquisa do gesto possibilita o entendimento dos princípios marciais e, concomitantemente, o aprimoramento dos golpes e das seqüências marciais padronizadas. Também promove a criatividade e a melhoria da condição física em consonância com os limites e possibilidades individuais, uma vez que cada estudante desenvolve seu estudo explorando os próprios recursos e sem uma meta quantitativa a ser atingida.

- Jogo Marcial: O estudo das técnicas e princípios marciais em associação num contexto de jogo. Ainda que seja paradoxal a ludicidade no contexto marcial, sua presença pode contribuir na experiência combativa do gesto, pois através do jogo, ritualiza-se o aspecto aguerrido inerente ao gesto marcial (HUIZINGA, 2010). Assim, o jogo potencializa a dimensão lúdica em detrimento da dimensão prática de preparação para o combate. Afinal, "o jogo situa-se fora da sensatez da vida prática, nada tem a ver com a necessidade ou a utilidade, com o dever ou com a verdade" (HUIZINGA, 2010, p.177).

O jogo distancia-se do cenário real da vida, uma vez que cria uma dimensão imaginária distinta da realidade. Apesar de ocorrer no mundo, o 
jogo rejeita e ignora intencionalmente as condições do real, por ser uma atividade isolada do resto da existência, sendo praticada, de maneira geral, "dentro de limites precisos de tempo e de lugar" (CAILLOIS, 1990, p.26). Há um espaço próprio para o jogo acontecer e nada do que está fora desse espaço conta durante o período em que se está a jogar. No entanto, é preciso que o jogo não descaracterize por completo a arte marcial ou senão, corre-se o risco da perda da especificidade e, por conseqüência, não desenvolvimento das habilidades marciais.

Em diversas áreas de estudo, procura-se descrever e analisar o jogo de maneira a procurar nele uma função prática para a sua existência, algo exterior ao próprio jogo, uma utilidade ou serventia qualquer. Função que é sutilmente refutada:

O jogo não é exercício, ou mesmo uma experiência ou uma prova, a não ser por acréscimo. As faculdades que ele desenvolve beneficiam certamente esse treino suplementar, que além do mais é livre, intenso, agradável, criativo e protegido. Só que o jogo não tem por função específica o desenvolvimento de uma capacidade. A finalidade do jogo é o próprio jogo (CAILLOIS, 1990, p.193).

Não é simples introduzir o jogo no contexto marcial, pois a proximidade com o combate tende a afastar a ludicidade das artes marciais. Além disso, as especificidades e o desafio das técnicas exigem atenção e também podem gerar alguma tensão, impedindo o surgimento do estado de jogo.

Duas técnicas marciais facilitam este processo, pois transitam com bastante fluidez entre o jogo, o teatro, o combate e a dança. Trata-se dos estilos marciais chineses que interpretam animais e a capoeira, pois além de elementos marciais, possuem espontaneamente outros de ordem lúdica e expressiva (SANTOS, 2014).

Em alguns estilos marciais de origem chinesa, a própria técnica de interpretar um animal em contexto de combate, já transporta o praticante 
para o mundo do jogo, lugar privilegiado de aprendizado e contentamento humano.

$\mathrm{Na}$ capoeira, a musicalidade e a ocupação do espaço vazio do outro, concorrerá para uma gestualidade que não visa ações de oposição através do contato corporal, mas de composição e diálogo, potencializando extraordinariamente o estado de jogo.

A mímesis também é extremamente favorável para a criação do estado de jogo, já que a mímesis dos gestos do outro pressupõe a saída de si para adoção do comportamento alheio. Este jogo de mímesis pode ser feito em dupla, trio, quarteto ou em grupos maiores.

O jogo é uma maneira instigante de abordar e propor um conhecimento, pois ele torna mais fácil o que de outro modo poderia ser difícil ou extenuante, aguçando o entusiasmo pelo movimento. Também estimula a exploração e ampliação das técnicas e possibilita aos estudantes realizar mais trocas de experiências entre si.

No entanto, é preciso estudar profundamente a marcialidade para poder transmutá-la em jogo, pois o desafio de ensinar a arte marcial através do jogo é equilibrar o prazer intrínseco do mesmo com o desenvolvimento técnico do gesto marcial.

\section{Desfecho}

É um desafio aproximar-se do aspecto artístico e lúdico das artes marciais, pois suas origens e sua expansão atual estão imbricadas na dimensão pragmática da eficiência marcial e/ou do desempenho esportivo. Em ambos os contextos, os atributos marciais tendem a suprimir a dimensão artística e lúdica do gesto, mas é justamente esta tentativa que pode vir a ampliar significativamente suas possibilidades pedagógicas.

No entanto, é importante apontar que a arte e o jogo por si sós se justificam! A opção por ensinar com arte e jogo não deve se fundar prioritariamente pelo desejo de aprimoramento do processo de ensino e 
aprendizagem, mas sim pelo reconhecimento da grandeza e singularidade da arte e do jogo.

As atividades apresentadas aqui visam reforçar e demonstrar a relação entre arte, jogo e arte marcial, contribuindo para elaboração de novas e distintas possibilidades de ensinar arte marcial. Trata-se de uma proposta particular que está relacionada ao perfil dos estudantes que estão inseridos em um curso de formação em educação física, por isso, precisa ser analisada à luz desta particularidade e também da intenção de desenvolver os aspectos artísticos e lúdicos do gesto marcial.

Por fim, é preciso enaltecer as artes marciais como práticas significativas no âmbito da formação humana e também na formação profissional em educação física, pois através da arte marcial é possível experimentar de maneira controlada, a agressividade e a ferocidade presente em cada um de nós.

\section{Referências}

BREDA, Mauro Eduardo de Jesus Gonçalves; GALATTI, Larissa Rafaela; SCAGLIA, Alcides José; PAES, Roberto Rodrigues. Pedagogia do esporte aplicada às lutas. São Paulo: Phorte, 2010.

BULFINCH, Thomas. O livro de ouro da mitologia: (a idade da fábula) histórias de deuses e heróis. Rio de Janeiro: Ediouro, 2000.

CAILLOIS, Roger. Os jogos e os homens: a máscara e a vertigem. Lisboa: Edições Cotovia, 1990.

CORREIA, Walter Roberto; FRANCHINI, Emerson. Produção acadêmica em lutas, artes marciais e esportes de combate. Motriz, Rio Claro, v.16, n. 1, p. 1-9, jan./mar. 2010.

DEL VECCHIO, Fabrício Boscolo; FRANCHINI, Emerson. Lutas, artes marciais e esportes de combate: possibilidades, experiências e abordagens no currículo da educação física. In: SOUZA NETO, Samuel; HUNGER, Dagmar. (Orgs.). Formação profissional em educação física: estudos e pesquisas. Rio Claro: Biblioética, 2006. p. 99-108.

ESPARTERO, Julián. Aproximación histórico-conceptual a los deportes de lucha. In: VILLAMÓN, Miguel. (Org.). Introducción al Judo. Barcelona: Editorial Hispano Europea, 1999. 
FENSTERSEIFER, Paulo Evaldo. Técnica. In: GONZÁLEZ, Fernando Jaime; FENSTERSEIFER, Paulo Evaldo. (Orgs.). Dicionário Crítico de Educação Física. Ijuí: Ed. Unijuí, 2014.

FERREIRA, Aurélio Buarque de Holanda. Dicionário Aurélio da Língua Portuguesa. Curitiba: Positivo, 2005.

GAGNEBIN, Jeanne Marie. Do conceito de mímesis no pensamento de Adorno e Benjamin. In: Janeiro: Imago, 2005. . Sete aulas sobre linguagem, memória e história. Rio de

GOMBRICH, Ernst Hans Josef. A História da arte. Rio de Janeiro: LTC, 1999.

GOMES, Mariana Simões Pimentel. Procedimentos pedagógicos para o ensino das lutas: contextos e possibilidades. 2008. 139f. Dissertação (Mestrado em Educação Física) - Unicamp, Faculdade de Educação Física. Campinas. 2008.

HOMERO. A Ilíada em forma de narrativa. Rio de Janeiro: Ediouro, 2005.

HUIZINGA, Johan. Homo Ludens: o jogo como elemento da cultura. São Paulo: Perspectiva, 2010.

LABAN, Rudolf. Domínio do movimento. São Paulo: Summus, 1978.

LEE, Bruce. Entrevista a Pierre Berton Show - The Mandarim Superstar concedida em 9 de Dezembro de 1971. [S. l.: s. n.], 1971. 1 vídeo (24 min). Disponível em: <https://www.youtube.com/watch?v=VEGTk1qGnRg> Acesso em: 20 mai. 2018.

PESSOA, Fernando. Livro do desassossego: composto por Bernardo Soares, ajudante de guarda-livros na cidade de Lisboa. São Paulo: Companhia das Letras, 2006.

REID, Howard; CROUCHER, Michael. O caminho do guerreiro: o paradoxo das artes marciais. São Paulo: Cultrix, 1983.

ROBLE, Odilon José; NUNOMURA, Myrian; OLIVEIRA, Maurício Santos. O que a ginástica artística tem de artística? Considerações a partir de uma análise estética. Revista Brasileira de Educação Física e Esporte. São Paulo, out-dez. 2013. p. 543551.

ROSSETO, Robson; ANDRAUS, Mariana Baruco Machado. Improvisação a partir de técnicas do sistema de gongfu louva-a-deus como espaço para a investigação corpóreo-estética do artista da cena. Moringa - Artes do Espetáculo, p.79-93, volume 6, número 2, jul-dez 2015.

RUFINO, Luis Gustavo Bonatto; DARIDO, Suraya Cristina. Pedagogia do esporte e das lutas: em busca de aproximações. Revista Brasileira de Educação Física e Esporte, p.283-300, 2012. 
SANTOS, Gilbert de Oliveira. Aproximações técnicas entre as artes marciais chinesas e a capoeira. Revista Digital EFDeportes.com, Buenos Aires, ano 19, n. 198, nov. 2014.

SANTOS, Gilbert de Oliveira; BRAGANÇA, Analiz Pergolizzi Gonçalves de. O Estudo e a Prática do Tai Chi Chuan: a busca de si através do gesto. EXTRAMUROS Revista de Extensão da UNIVASF (Petrolina), v. 6, n. 2, p. 037$051,2019$.

SILVA, Ana Márcia; LAZZAROTTI FILHO, Ari; ANTUNES, Priscilla de Cesaro. Práticas Corporais. In: GONZÁLEZ, Fernando Jaime; FENSTERSEIFER, Paulo Evaldo. (Orgs.). Dicionário Crítico de Educação Física. Ijuí: Ed. Unijuí, 2014.

VALÉRY, Paul. Degas Dança Desenho. São Paulo: Cosac \& Naify Edições, 2003.

WULF, Christoph. Antropologia da Educação. Campinas, SP: Editora Alínea, 2005. 